\title{
VARIABILIDADE GENÉTICA EM ACESSOS DE Capsicum chinense POR MEIO DE MARCADORES ISOENZIMÁTICOS E RAPD
}

\section{GENETIC VARIABILITY IN Capsicum chinense ACCESSES BY ISOENZYMATIC AND RAPD MARKERS}

\author{
Cristina Soares de SOUZA ${ }^{1}$ \\ Adilson Ricken SCHUELTER ${ }^{2}$ \\ Fernando Luiz FINGER ${ }^{3}$ \\ Vicente Wagner Dias CASALI ${ }^{4}$
}

\begin{abstract}
RESUMO
As espécies de pimenta do gênero Capsicum têm sido cultivadas por vários séculos, encontrando-se frutos pungentes ou doces, dependendo da presença de um grupo de alcalóides, denominado capsaicinóide. Dentre as cinco espécies cultivadas, Capsicum chinense é uma das mais empregadas, sendo nativa da região amazônica. Essa espécie é caracterizada por apresentar tamanhos, formas e massa dos frutos bastante variados, por conter diferentes concentrações de capsaicinóides, além de serem ricos nas vitaminas A e C. Embora seja destacada a importância dessas plantas condimentares e medicinais, investigações sobre a variabilidade genética e potencial para futuros programas de melhoramento, ainda são incipientes. Sendo assim, o presente trabalho teve como objetivos estudar a variabilidade genética de acessos pungentes e com frutos doces por meio de marcadores isoenzimáticos e RAPD. Um total de 10 acessos de Capsicum chinense foram cultivados, sendo metade deles pungentes, em bandejas contendo substrato comercial em condições de casa de vegetação, tendo sido coletado um "pool" de tecido foliar para as análises de marcadores isoenzimáticos e RAPD. Os resultados das análises de marcadores isoenzimáticos e RAPD evidenciaram a ocorrência de variabilidade genética, e a análise de divergência pelos métodos do UPGMA e de Tocher propiciou a formação de dois grupos, com um deles composto por três subgrupos. A maior divergência genética foi observada entre os acessos P2 (BGH4289-44) e P8 (BGH4223-39), enquanto que os mais similares foram os acessos P1 (BGH1716-17) e P6 (BGH171616). A análise da divergência genética evidencia que o cruzamento de $\mathrm{P} 2$ (BGH4289-44) com os demais acessos estudados pode propiciar resultados promissores na obtenção de segregantes superiores no melhoramento para caracteres de frutos.

Palavras-chave: pimenta; pungência; marcadores genéticos; diversidade genética.
\end{abstract}

\section{ABSTRACT}

The pepper species from Capsicum genus have been cultivated for centuries, found in sweet or pungent fruits, depending on the presence of a group of alkaloids named as capsaicinoid. Among the five cultivated species, Capsicum chinense is one of the most used, being native from the Amazon region. This species is characterized for its varied sizes, shapes and fruits weight, by containing different concentrations of capsaicinoid,besides being rich in vitamins $\mathrm{A}$ and $\mathrm{C}$. Despite of the importance of these spice and medicinal plants, investigations regarding the genetic variability and future potential for breeding programs are still incipient. Thus, the present work had the objective to evaluate the genetic variability of pepper pungent accesses with sweet fruits, using isoenzymatic and RAPD markers. A total of 10 accesses of Capsicum chinense, being half of them pungent, were cultivated in trays containing commercial substrate at greenhouse, and a pool of leaf tissue was collected for further isoenzymes and RAPD analyses. The results of isoenzymatic and RAPD markers demonstrated the occurrence of genetic variability, and divergence analysis through methods of UPGMA and Tocher led the formation of two clusters with one these groups composed by three subgroups. The highest genetic divergence was observed between the accesses P2 (BGH4289-44) and P8 (BGH4223-39), whereas the most similar ones were P1 (BGH1716-17) and P6 (BGH1716-16). The genetic divergence points out that the crossing between the accesses P2(BGH4289-44) with all the others accesses studied should provide promising results to obtain superior segregant plants for better fruit traits through breeding.

Key-words: pepper; pungency; genetic markers; genetic diversity.

\footnotetext{
${ }^{1}$ Pós-doutoranda da Empresa de Pesquisa Agropecuária de Minas Gerais, EPAMIG, Avenida Santa Cruz, 500. CEP: 37.780-000, Caldas, MG, Brasil. E-mail: cristina.genetica@gmail.com. Autor para correspondência.

${ }^{2}$ D.Sc. Pesquisador da Cooperativa Central de Pesquisa Agrícola, COODETEC, BR 467, Km 98. CEP: 85.813-450, Cascavel, PR, Brasil. Email: adilson_schuelter@yahoo.com.br

${ }^{3}$ Ph.D. Prof. Adjunto do Departamento de Fitotecnia, Universidade Federal de Viçosa (UFV), Avenida P.H. Rolfs s/n. CEP: 36.571-000, Viçosa, MG, Brasil. E-mail: ffinger@ufv.br

${ }^{4}$ Ph.D. Prof. Adjunto do Departamento de Fitotecnia, Universidade Federal de Viçosa (UFV), Avenida P.H. Rolfs s/n. CEP: 36.571-000, Viçosa, MG, Brasil. E-mail: vwcasali@ufv.br
} 
SOUZA, C.S. et al. Variabilidade genética em acessos de...

\section{INTRODUÇÃO}

As espécies do gênero Capsicum, que englobam pimentas e pimentões, têm sido cultivadas por séculos, sob diversas condições de cultivo e formas de utilização. Os frutos têm sido empregados para consumo in natura, na fabricação de condimentos, no processamento de pratos ou de alimentos industrializados (Souza \& Casali, 1984). Essa ampla utilização dos frutos deve-se à elevada variabilidade no formato, cores e composição química (Lannes, 2005). Dentre os atributos dos frutos, a pungência, típica desse gênero, deve-se à presença do alcalóide capsaicina, que apresenta importância econômica nas indústrias alimentícia e farmacêutica, sendo que as pimentas mais pungentes, geralmente, têm maior valor comercial (Monsereenusorn et al., 1982). Os frutos apresentam também alto valor vitamínico, destacando-se principalmente pelo conteúdo de vitaminas A e C (Heiser Jr, 1976) e por apresentarem potencial de ornamentação, pela ampla variabilidade de cores, formas e tamanhos dos frutos (Brickell, 1989).

Embora seja reconhecida a importância dessas plantas condimentares e medicinais, investigações sobre a variabilidade genética e potencial para futuros programas de melhoramento, ainda são incipientes, uma vez que o gênero Capsicum abrange espécies domesticadas, semidomesticadas e silvestres, que foram pouco ou não foram, ainda, caracterizadas em termos de seu potencial fitotécnico (Reifschneider, 2000). Estudos recentes obtidos por Lannes (2005), Pereira(2007) e Schuelter et al. (2010) empregando acessos de Capsicum chinense do Banco de Germoplasma da Universidade Federal de Viçosa detectaram a existência de variabilidade genética para atributos de importância econômica em frutos, como a cor e pungência, que atendem aos padrões de exigência da "American Spice Trade Association" (ASTA) para processamento. Portanto, futuros programas de melhoramento devem incluir esta espécie como fornecedora de genes, pois não há barreira reprodutiva entre as espécies domesticadas (Pickersgill, 1980; Casali \& Couto, 1984), além de estar bem estabelecida a metodologia de cruzamentos controlados entre elas (Greenleaf, 1986)

O estudo da variabilidade genética em espécies vegetais tem sido realizado por meio de caracteres morfoagronômicos e marcadores moleculares. O emprego de marcadores em nível gênico constitui-se em uma importante ferramenta de auxílio a propostas de conservação de espécies, bem como em diferentes etapas de programas de melhoramento genético. Marcadores moleculares ligados a genes de importância econômica vêm sendo amplamente utilizados nas mais diferentes culturas de interesse econômico, incluindo as do gênero Capsicum (Lefebvre et al., 1995; Prince et al., 1995; Djian -Caporalinoet al., 2001; Huh et al., 2001; Lefebvre et al., 2001; Ben-Chaimet al., 2006), visando à transferência e piramidação de genes para varieda- des cultivadas. Além do que, estudos de diversidade genética têm sido realizados com o intuito de caracterizar molecularmente os bancos de germoplasma, permitindo aos melhoristas selecionar genitores mais divergentes e, consequentemente, novos genótipos recombinantes com caracteres superiores poderão ser gerados.

Nas espécies desse gênero, as técnicas de marcadores isoenzimáticos e moleculares em nível de DNA, tais como marcadores RFLP (Paran et al., 1998; Lefebvre et al., 1995), RAPD (Rodriguez et al., 1999; Lannes, 2005; Costa et al., 2008), AFLP (Kochieva\&Ryzhova, 2003; Guzmán et al., 2005), SSR (Minamiyama et al., 2007; Yi et al., 2006), entre outras novas estratégias de análise (Lee et al., 2009), são bem definidas e têm sido empregadas para diferentes finalidades.

Diante do exposto, o presente trabalho teve como objetivo avaliar a variabilidade genética de acessos de pimenta (Capsicum chinense), promissores para melhoramento genético de caracteres de frutos estudados por Lannes (2005), empregandose marcadores RAPD e isoenzimas.

\section{MATERIAL E MÉTODOS \\ Material e condições de cultivo}

Dez acessos de Capsicum chinense (Tabela 1), dos quais, cinco pungentes e cinco doces foram selecionados com base na pungência dos frutos, conforme determinado por Lannes (2005).

A caracterização isoenzimática e a de DNA, pela técnica de RAPD, dos acessos de $C$. chinense especificados na Tabela 1 foram realizadas a partir de tecidos de folhas jovens de plântulas com 60 dias após a semeadura em bandejas com substrato comercial em condições de casa de vegetação. A análise de marcadores isoenzimáticos foi realizada no Laboratório de Melhoramento de Hortaliças da Universidade Federal de Viçosa e de RAPD, no Laboratório de Biotecnologia da Universidade Paranaense - Campus Toledo.

\section{Marcadores isoenzimáticos}

Folhas de 10 plântulas diferentes para cada acesso foram coletadas e transportadas até o Laboratório em isopor sob condições de baixa temperatura $\left(4^{\circ} \mathrm{C}\right) \mathrm{e}$, na sequência, submetidas à maceração e extração das enzimas conforme descrição de Alfenas (1991). Na sequência, o macerado foi colocado em contato a segmentos de papel cromatográfico Whatman $3 \mathrm{M}$, sendo transferido por capilaridade. Os retângulos contendo as amostras foram acondicionados em microtubos $(2 \mathrm{~mL})$ e armazenados em ultrafreezer $\left(-80^{\circ} \mathrm{C}\right)$.

Os fenótipos dos locos isoenzimáticos dos 10 acessos de Capsicum chinense foram determinados após eletroforese, em gel de amido hidrolisado de batata (Sigma) a 12\%, conforme descrição de Alfenas (1991), para os sistemas malato desidrogenase $(\mathrm{MDH})$, xiquimato desidrogenase (SHDH), isocitrato desidrogenase (IDH), fosfoglucose isome- 
SOUZA, C.S. et al. Variabilidade genética em acessos de...

rase $(P G I)$, fosfoglucomutase (PGM), peroxidase $(\mathrm{PO})$, esterase (EST), fosfatase ácida (ACP), glucose 6 fosfato desidrogenase (G6PDH), glutamato desidrogenase $(\mathrm{GDH})$ e glutamato-oxalato transaminase (GOT).

Os padrões de bandas identificados nos géis, para cada sistema isoenzimático, foram analisados mediante o emprego de régua graduada, medindo-se a distância percorrida após a corrida eletroforética para que fosse possível estimar a mobilidade relativa (Mr). A estimação da mobilidade relativa (Mr) de uma referida banda consistiu na divisão da distância percorrida por uma banda específica, pela distância percorrida por uma banda de maior migração, presente na maioria dos acessos.

\section{Marcadores RAPD}

Tecidos foliares de plântulas cultivadas em condições de casa de vegetação foram submetidos à extração e purificação do DNA genômico empregando-se a metodologia de Doyle \& Doyle (1991). Para cada acesso foram empregados tecidos foliares de cinco plântulas, os quais foram coletados e extraídos em 'bulk'. Após a extração e purificação do DNA, realizou-se a verificação da qualidade e da concentração da solução de DNA por meio do emprego da eletroforese em gel de agarose a $1 \% \mathrm{e}$ espectrofotometria. As amostras de soluções de DNA de boa qualidade foram diluídas para a concentração de trabalho $5 \mathrm{ng} \mathrm{L}^{-1}$ para proceder-se à amplificação de DNA pela técnica de RAPD.

O protocolo da técnica de marcadores RAPD, proposta por Williams et al. (1990), consistiu no emprego de $25 \mu$ para cada reação em cadeia da polimerase, contendo $10 \mathrm{mM}$ Tris $\mathrm{HCl}(\mathrm{pH} 8,3)$; $50 \mathrm{mM} \mathrm{KCl} ; 2,8 \mathrm{mM} \mathrm{MgCl}_{2} ; 0,2 \mathrm{mM}$ de cada um dos desoxinucleotídeos (dATP, dTTP, dGTP, dCTP); 0,2 mM primers decâmeros; 5-10 ng DNA genômico e uma unidade de Taq polimerase. O DNA foi amplificado em tubos PCR $(0,2 \mathrm{~mL})$ em termociclador Termo Híbrido PX2. O programa de amplificação do DNA consistiu de uma etapa de desnaturação a 92 ${ }^{\circ} \mathrm{C}$ por um minuto, pareamento a $35^{\circ} \mathrm{C}$ por um mi- nuto e etapa de extensão a $72{ }^{\circ} \mathrm{C}$ durante dois minutos. Os produtos de 42 ciclos de amplificação foram separados por eletroforese em gel de agarose $(1,2 \%)$, contendo $0,2 \mu \mathrm{M}$ de brometo de etídio, em tampão TAE 0,5\%. As imagens foram registradas e armazenadas em sistema de fotodocumentação, para posterior análise do padrão de bandas identificadas, para os 10 acessos de Capsicum chinense (Tabela 3).

\section{Análise estatística dos marcadores isoenzimáti- cos e RAPD}

A dissimilaridade dos acessos de Capsicum chinense foi avaliada pelo Programa Genes (Cruz, 2006ab), empregando-se o complemento aritmético do índice de Jaccard (Tabela 4). Na sequência, empregou-se os Método de Ligação Média entre Grupos (UPGMA) e de Otimização de Tocher com o intuito de agrupar os diferentes acessos.

\section{RESULTADOS E DISCUSSÃO}

Dos 11 sistemas isoenzimáticos analisados, GDH, PGM, PO, EST, PGI, SKDH, G6PDH, IDH, $\mathrm{MDH}$ e GOT puderam ser fenotipados, devido à resolução e reprodutibilidade dos resultados. Destes, em GDH, PGM, PO, EST, PGI e SKDH foram detectados 17 alelos (Tabela 2), que puderam ser empregados para caracterizar os acessos pungentes e doces. $\mathrm{O}$ número de alelos polimórficos variou de cinco para o sistema PGM até dois para PO, EST e PGI.

A revelação da atividade da enzima $P G M$ resultou na formação de duas regiões fortemente coradas no gel (Figura 1A). Na região I, representada pelas enzimas de migração mais rápida, foram encontrados dois alelos, e três, na região II. Estes resultados permitiram identificar cinco padrões de bandas, nos quais se detectou, apenas, a presença de locos homozigóticos para a enzima PGM, não permitindo inferir quanto à estrutura da enzima. Contudo, outros estudos têm revelado que PGM é uma enzima monomérica, apresentando dois locos gênicos (Sawazakiet al., 1997; Brune et al., 1998; Lopes et al., 2002).

TABELA 1- Acessos de pimenta (Capsicum chinense) empregados nas análises genéticas.

\begin{tabular}{|llll|}
\hline Acesso/No & Genitor & Grupo & Local de coleta \\
\hline BGH 1716-17 & P1 & Pungente & Pindaré-Mirim / MA \\
\hline BGH 4289-44 & P2 & Pungente & Rondonópolis/ MT \\
\hline BGH 4733-54 & P3 & Pungente & Manaus/ AM \\
\hline BGH 5012-72 & P4 & Pungente & Água Branca / AL \\
\hline BGH 7295-101 & P5 & Pungente & Viçosa /MG \\
\hline BGH 1716-16 & P6 & Doce & Pindaré-Mirim / MA \\
\hline BGH 4201-32 & P7 & Doce & Belém / PA \\
\hline BGH 4223-39 & P8 & Doce & IAC- SP \\
\hline BGH 6233-85 & P9 & Doce & Brasília /DF \\
\hline BGH 6378-98 & P10 & Doce & Boca do Janacanam /AM \\
\hline
\end{tabular}


SOUZA, C.S. et al. Variabilidade genética em acessos de...

TABELA 2 - Caracterização de 10 acessos de pimenta (Capsicum chinense) quanto à presença e ausência de bandas pela análise de marcadores isoenzimáticos.

\begin{tabular}{|c|c|c|c|c|c|c|c|c|c|c|}
\hline Marcador/Genitor & $\mathbf{P} 1^{\mathrm{a}}$ & P2 & P3 & P4 & P5 & P6 & P7 & P8 & P9 & P10 \\
\hline $\mathrm{GDHa}^{\mathrm{b}}$ & 0 & 0 & 0 & 0 & 0 & 0 & 0 & 0 & 1 & 0 \\
\hline $\mathrm{GDHb}$ & 1 & 0 & 1 & 1 & 1 & 1 & 1 & 1 & 0 & 1 \\
\hline GDHc & 0 & 1 & 0 & 0 & 0 & 0 & 0 & 0 & 0 & 0 \\
\hline PGMa & 1 & 0 & 0 & 1 & 1 & 1 & 1 & 1 & 1 & 1 \\
\hline PGMb & 0 & 1 & 0 & 0 & 0 & 0 & 0 & 0 & 0 & 0 \\
\hline PGMc & 0 & 0 & 1 & 0 & 0 & 0 & 0 & 0 & 0 & 0 \\
\hline PGMd & 0 & 0 & 1 & 1 & 0 & 0 & 0 & 1 & 1 & 0 \\
\hline PGMe & 1 & 1 & 0 & 0 & 1 & 1 & 1 & 0 & 0 & 1 \\
\hline $\mathrm{POa}$ & 0 & 0 & 1 & 1 & 1 & 1 & 0 & 1 & 0 & 0 \\
\hline $\mathrm{POb}$ & 1 & 1 & 0 & 0 & 0 & 1 & 1 & 0 & 1 & 1 \\
\hline ESTa & 1 & 0 & 1 & 1 & 1 & 1 & 1 & 1 & 1 & 1 \\
\hline ESTb & 0 & 1 & 0 & 0 & 0 & 0 & 0 & 0 & 0 & 0 \\
\hline PGla & 0 & 1 & 0 & 0 & 0 & 0 & 0 & 0 & 0 & 0 \\
\hline PGlb & 0 & 1 & 1 & 1 & 1 & 1 & 1 & 1 & 1 & 1 \\
\hline SKHa & 0 & 1 & 0 & 0 & 0 & 0 & 0 & 0 & 0 & 0 \\
\hline SHKb & 1 & 0 & 0 & 1 & 1 & 1 & 1 & 0 & 1 & 1 \\
\hline SHKc & 0 & 0 & 1 & 0 & 0 & 0 & 0 & 1 & 0 & 0 \\
\hline
\end{tabular}

${ }^{a}$ Acessos de pimenta: P1 (BGH 1716-17); P2 (BGH 4289-44); P3 (BGH4733-54); P4 (BGH 5012-72); P5 (BGH7295-101); P6 (BGH1716-16); P7 (BGH4201-32); P8 (BGH4223-39); P9 (BGH6233-85); P10 (BGH637898). ${ }^{b}$ Alelos detectados pelas análises de marcadores isoenzimáticos. (0) ausência e (1) presença de bandas. 
SOUZA, C.S. et al. Variabilidade genética em acessos de...

TABELA 3 - Caracterização de 10 acessos de pimenta (Capsicum chinense) quanto à presença e ausência de bandas pela análise de marcadores RAPD.

\begin{tabular}{|c|c|c|c|c|c|c|c|c|c|c|}
\hline Marcador/Genitor & $\mathbf{P} 1^{\mathrm{a}}$ & P2 & P3 & P4 & P5 & P6 & P7 & P8 & P9 & P10 \\
\hline $\mathrm{A} 1 \mathrm{a}^{\mathrm{b}}$ & 1 & 1 & 1 & 0 & 9 & 1 & 1 & 1 & 1 & 1 \\
\hline $\mathrm{A} 1 \mathrm{~b}$ & 1 & 1 & 1 & 0 & 9 & 1 & 1 & 1 & 1 & 1 \\
\hline A1c & 0 & 0 & 0 & 1 & 9 & 0 & 0 & 0 & 1 & 1 \\
\hline A1d & 0 & 0 & 0 & 0 & 0 & 0 & 0 & 0 & 0 & 0 \\
\hline A5a & 1 & 0 & 0 & 0 & 1 & 1 & 1 & 0 & 1 & 1 \\
\hline$A 5 b$ & 0 & 0 & 0 & 0 & 0 & 0 & 0 & 0 & 0 & 0 \\
\hline A5c & 1 & 0 & 1 & 1 & 1 & 1 & 1 & 1 & 1 & 1 \\
\hline A7a & 0 & 1 & 1 & 1 & 0 & 0 & 0 & 1 & 1 & 1 \\
\hline A7b & 1 & 1 & 1 & 0 & 9 & 1 & 1 & 1 & 1 & 9 \\
\hline A7c & 1 & 1 & 1 & 1 & 1 & 1 & 1 & 1 & 1 & 1 \\
\hline A7d & 0 & 0 & 0 & 0 & 0 & 0 & 0 & 0 & 0 & 0 \\
\hline A8a & 0 & 1 & 1 & 1 & 9 & 0 & 0 & 0 & 1 & 9 \\
\hline A8b & 1 & 1 & 1 & 1 & 9 & 1 & 1 & 1 & 1 & 9 \\
\hline A8c & 1 & 0 & 1 & 1 & 9 & 0 & 1 & 0 & 1 & 9 \\
\hline A8d & 1 & 0 & 0 & 0 & 1 & 1 & 1 & 0 & 1 & 1 \\
\hline A9a & 1 & 0 & 1 & 1 & 1 & 0 & 0 & 1 & 1 & 1 \\
\hline A9b & 1 & 0 & 1 & 0 & 1 & 1 & 1 & 1 & 1 & 1 \\
\hline $\mathrm{A} 10 \mathrm{a}$ & 1 & 1 & 0 & 1 & 1 & 1 & 1 & 0 & 0 & 0 \\
\hline $\mathrm{A} 10 \mathrm{~b}$ & 1 & 1 & 1 & 1 & 1 & 1 & 1 & 1 & 1 & 1 \\
\hline $\mathrm{A} 14 \mathrm{a}$ & 1 & 1 & 9 & 1 & 1 & 1 & 1 & 0 & 1 & 1 \\
\hline $\mathrm{A} 14 \mathrm{~b}$ & 0 & 1 & 0 & 1 & 0 & 0 & 0 & 0 & 0 & 0 \\
\hline A15a & 0 & 0 & 1 & 1 & 1 & 0 & 0 & 1 & 0 & 0 \\
\hline $\mathrm{A} 15 \mathrm{~b}$ & 1 & 0 & 1 & 0 & 0 & 1 & 1 & 1 & 0 & 1 \\
\hline $\mathrm{A} 15 \mathrm{c}$ & 0 & 1 & 0 & 0 & 1 & 1 & 0 & 0 & 0 & 0 \\
\hline B12a & 0 & 1 & 1 & 0 & 1 & 0 & 0 & 1 & 1 & 0 \\
\hline B12b & 1 & 0 & 0 & 1 & 1 & 1 & 0 & 1 & 1 & 0 \\
\hline B12c & 1 & 1 & 1 & 0 & 1 & 1 & 1 & 1 & 1 & 1 \\
\hline B12d & 1 & 0 & 1 & 1 & 0 & 1 & 1 & 1 & 1 & 0 \\
\hline B18a & 1 & 0 & 1 & 1 & 9 & 0 & 0 & 0 & 1 & 0 \\
\hline $\mathrm{K} 17 \mathrm{a}$ & 0 & 1 & 0 & 0 & 1 & 0 & 1 & 0 & 9 & 1 \\
\hline K17b & 0 & 0 & 0 & 0 & 0 & 0 & 0 & 1 & 9 & 0 \\
\hline K17c & 1 & 0 & 1 & 0 & 0 & 1 & 1 & 0 & 9 & 0 \\
\hline K17d & 0 & 0 & 1 & 0 & 0 & 0 & 0 & 1 & 9 & 1 \\
\hline K17e & 1 & 1 & 1 & 1 & 1 & 1 & 0 & 0 & 9 & 1 \\
\hline AB3a & 1 & 0 & 1 & 1 & 0 & 1 & 1 & 1 & 1 & 1 \\
\hline AB3b & 0 & 0 & 0 & 0 & 1 & 0 & 1 & 0 & 0 & 0 \\
\hline AB3c & 0 & 0 & 0 & 1 & 0 & 1 & 1 & 0 & 1 & 0 \\
\hline AB3d & 0 & 0 & 0 & 0 & 1 & 0 & 0 & 0 & 1 & 1 \\
\hline A18a & 0 & 1 & 1 & 1 & 0 & 0 & 0 & 0 & 1 & 0 \\
\hline $\mathrm{A} 18 \mathrm{~b}$ & 0 & 0 & 0 & 1 & 0 & 0 & 1 & 0 & 1 & 1 \\
\hline A11a & 0 & 1 & 1 & 1 & 1 & 0 & 0 & 0 & 0 & 0 \\
\hline $\mathrm{A} 11 \mathrm{~b}$ & 0 & 1 & 1 & 0 & 1 & 0 & 0 & 1 & 1 & 0 \\
\hline B7a & 1 & 0 & 0 & 1 & 1 & 1 & 0 & 1 & 1 & 0 \\
\hline B7b & 1 & 0 & 1 & 0 & 1 & 1 & 1 & 1 & 1 & 1 \\
\hline
\end{tabular}

${ }^{a}$ Acessos de pimenta: P1 (BGH1716-17); P2 (BGH4289-44); P3 (BGH4733-54); P4 (BGH 5012-72); P5 (BGH7295-101); P6 (BGH1716-16); P7 (BGH4201-32); P8 (BGH4223-39); P9 (BGH6233-85); P10 (BGH637898). ${ }^{b}$ Alelos detectados pelas análises de marcadores RAPD. (0) ausência; (1) presença de bandas e (9) amostras indeterminadas. 
SOUZA, C.S. et al. Variabilidade genética em acessos de...

(A)

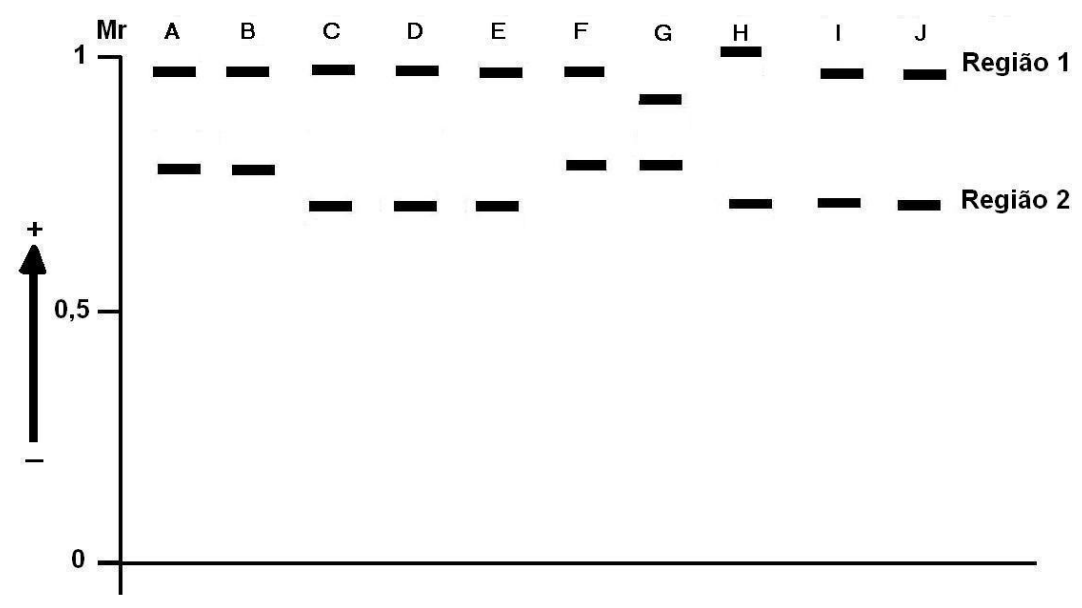

(B)

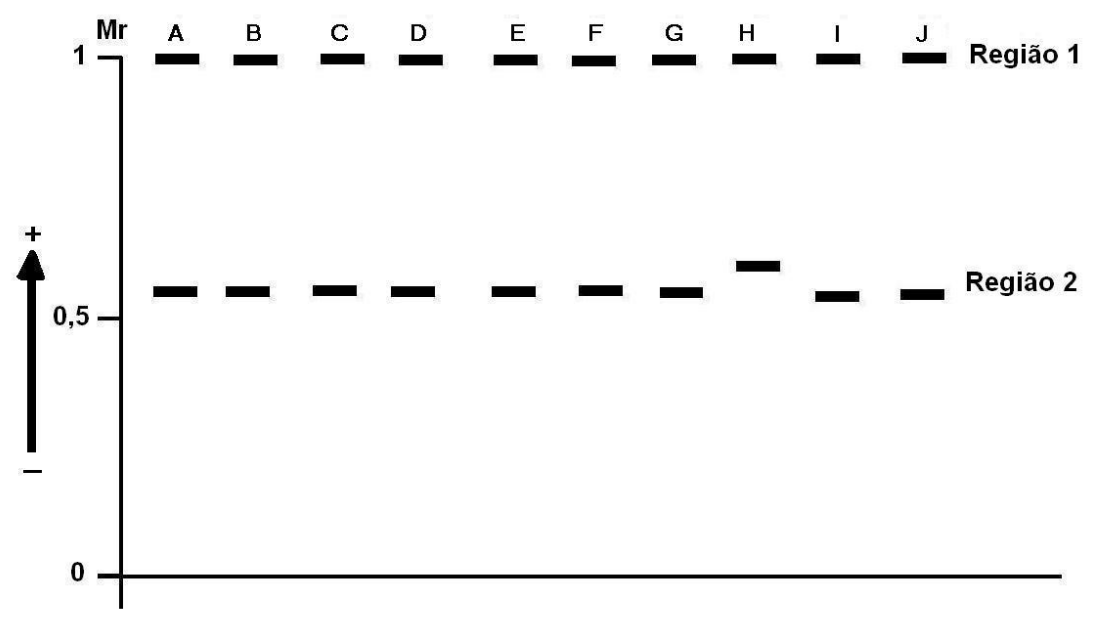

FIGURA 1 - Zimogramas obtidos para as isoenzimas [(A) - PGM; (B) - PGI], observadas em acessos de pimenta (Capsicum chinense). Sequência dos acessos: A) P9 (BGH6233-85); B) P8 (BGH4223-39); C) P7 (BGH4201-32); D) P6 (BGH1716-16); E) P5 (BGH7295-101); F) P4 (BGH 5012-72); G) P3 (BGH 4733-54); H) P2 (BGH 4289-44); I) P1 (BGH1716-17); J) P10 (BGH6378-98). 
SOUZA, C.S. et al. Variabilidade genética em acessos de...

TABELA 4 -Estimativas de dissimilaridade genética entre pares de acessos de pimenta (Capsicum chinense) calculados por meio do complemento do Índice de Jaccard.

\begin{tabular}{|llllllllll|}
\hline Acessos & P2 & P3 & P4 & P5 & P6 & P7 & P8 & P9 & P10 \\
\hline P1 (BGH1716-17) & 0.73 & 0.50 & 0.55 & 0.41 & 0.18 & 0.26 & 0.50 & 0.37 & 0.35 \\
\hline P2 (BGH 4289-44) & - & 0.68 & 0.76 & 0.68 & 0.70 & 0.73 & 0.78 & 0.70 & 0.72 \\
\hline P3 (BGH4733-54) & & - & 0.52 & 0.58 & 0.57 & 0.59 & 0.32 & 0.45 & 0.56 \\
\hline P4 (BGH5012-72) & & & - & 0.54 & 0.58 & 0.64 & 0.59 & 0.45 & 0.62 \\
\hline P5 (BGH7295-101) & & & & - & 0.40 & 0.50 & 0.54 & 0.47 & 0.46 \\
\hline P6 (BGH1716-16) & & & & & - & 0.26 & 0.50 & 0.45 & 0.42 \\
\hline P7 (BGH4201-32) & & & & & & - & 0.59 & 0.44 & 0.33 \\
\hline P8 (BGH4223-39) & & & & & & - & 0.46 & 0.55 \\
\hline P9 (BGH6233-85) & & & & & & & & - & 0.37 \\
\hline P10 (BGH6378-98) & & & & & & & & - \\
\hline
\end{tabular}

O zimograma representativo dos fenótipos correspondentes à isoenzima PGI (Figura 1B) apresenta duas regiões, sendo que a região I apresenta uma única banda na mesma posição do gel, sendo monomórfica. Por outro lado, na região II detectouse a presença de dois alelos, sendo que um dos alelos foi revelado, apenas, no acesso P2 (BGH4289-44). Segundo Brune et al. (1998), a isoenzima PGI é composta por duas cadeias polipeptídicas, de maneira que um heterozigoto deverá conter três bandas. De acordo com o mesmo autor, no presente trabalho os acessos são homozigotos para PGI.

\section{O sistema isoenzimático PO apresentou} atividade anódica e catódica nos tecidos foliares testados. No entanto, a falta de definição das bandas isoenzimáticas na porção catódica do gel fez com que sua análise fenotípica fosse descartada. A análise dos padrões de banda para este sistema na região anódica (Figura $2 \mathrm{~A}$ ), permitiu identificar três regiões, sendo que a de migração intermediária, denominada região II, mostrou-se polimórfica para uma enzima monomérica. Nas regiões I e III foram detectadas quatro e uma bandas respectivamente, para as quais os acessos foram monomórficos. Trabalho realizado por Schuelter (1996) para caracterizar a diversidade genética de Capsicum flexuosum por meio de caracteres morfoagronômicos e marcadores isoenzimáticos, detectou duas regiões de atividade para $\mathrm{PO}$, ao invés das três observadas neste estudo. Além do que, o mesmo autor observou polimorfismo para uma enzima dimérica na região com migração mais rápida. No presente trabalho não se observou polimorfismo para a região I, contudo todos os acessos apresentavam quatro bandas, podendo ter herança complexa e de difícil interpretação sem a realização de cruzamentos controlados. Deve-se destacar, ainda, que a caracterização para a região I foi dificultada pela presença de diferentes intensidades e pela fusão de bandas. Desta forma, as bandas do gel na região III poderão ser usadas para a caracterização de acessos de C. chinense.

O zimograma da enzima EST permite a visualização de três regiões de atividade (Figura 2B), porém detectou-se polimorfismo apenas na região III. Para esta região foram observados dois alelos, sendo um o mais frequente, encontrado em todos os acessos exceto em P2 (BGH4289-44). Este resultado para o sistema isoenzimático EST e, também, para PGI evidencia a presença de alelos mais raros, podendo ser resultado da maior distância genética do acesso P2 (BGH4289-44) em relação aos demais genótipos de $C$. chinense estudados.

O sistema glutamato desidrogenase (GDH) apresentou apenas uma região de atividade para a enzima (Figura 3A). Neste contexto, detectaram-se três alelos, sendo que oito acessos apresentaram o mesmo padrão de bandas e os acessos P2 (BGH4289-44) e P9 (BGH6233-85) foram distintos. Todos os indivíduos apresentaram apenas uma banda, evidenciando serem homozigotos, porém não foi possível inferir sobre o número de subunidades que compõem GDH. Contudo, estudos em plantas superiores indicam que $\mathrm{GDH}$ apresenta atividade na forma tetramérica (Scheid et al., 1980 apud Newton, 1983) ou hexamérica (Stone et al., 1979 apud Newton, 1983).

O sistema isoenzimático SKDH apresentou apenas uma região de migração com três alelos, sendo que todos os indivíduos encontram-se no estado homozigótico (Figura 3B). Do total de três padrões de banda identificados para a enzima, novamente, o acesso P2 (BGH4289-44) foi o único indivíduo a apresentar um determinado alelo. Estudos com plantas têm mostrado que se trata de uma enzima monomérica (Lopes et al., 2003; Gaia et al., 2007).

Para os sistemas isoenzimáticos em que os genótipos de $C$. chinense testados foram monomórficos, pode-se destacar que G6PDH e IDH (Figura $4 \mathrm{AeB}$ ) apresentaram apenas uma região de atividade, que se caracteriza por indivíduos homozigóticos para as respectivas enzimas. Já a enzima GOT apresentou duas bandas (Figura 5A), podendo ser caracterizada por duas regiões com fenótipos homozigóticos ou uma região contendo indivíduos em heterozigose para a enzima monomérica. Lopes et al. (2002) tiveram dificuldade para estabelecer o número de regiões e o mecanismo de herança de GOT em aceroleira (Malpighia emarginata). Já Lopes et al. (2003), estudando esse mesmo sistema, em erva de bicho (Polygonum punctatum) estabeleceram duas regiões, porém sem determinar o mecanismo de herança. 
SOUZA, C.S. et al. Variabilidade genética em acessos de...

(A)

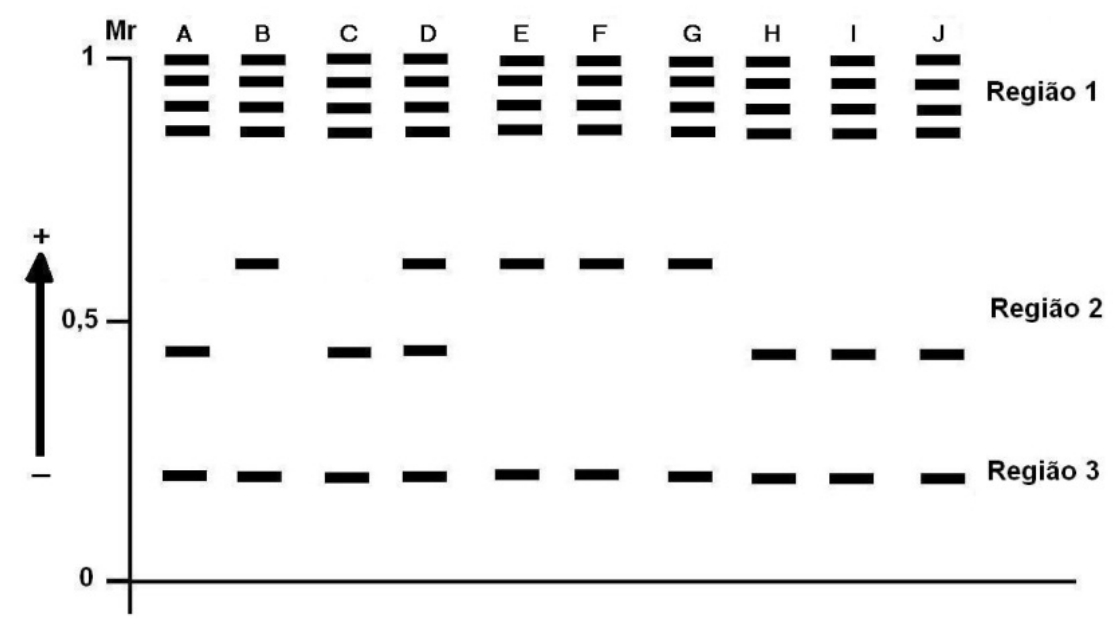

(B)

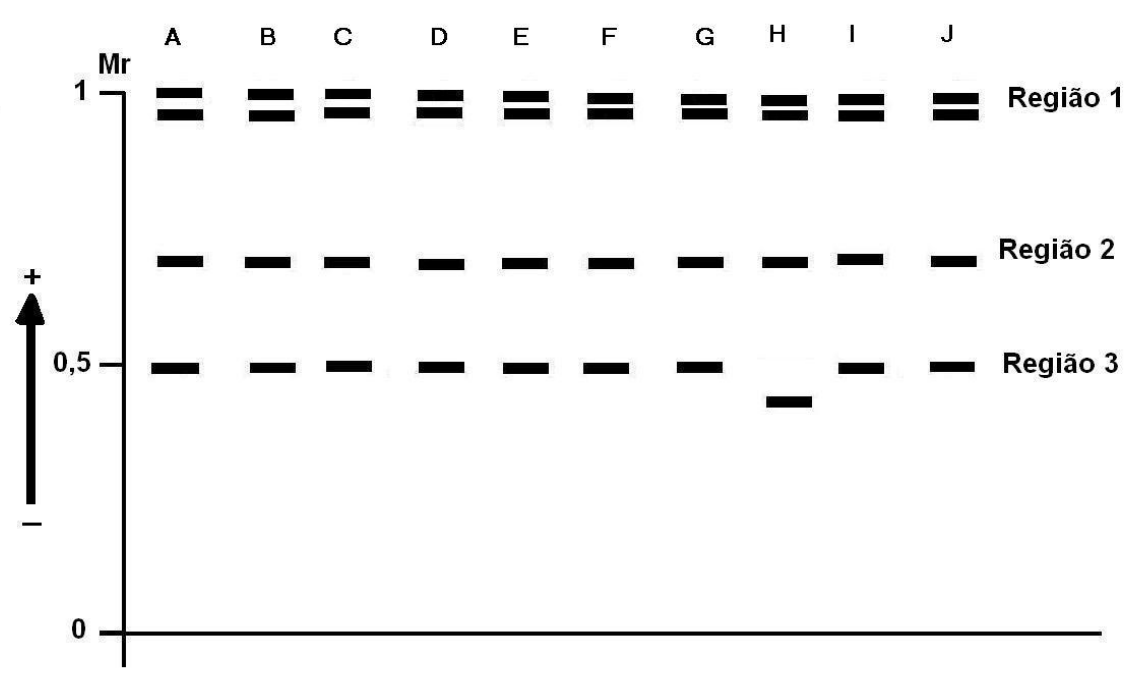

FIGURA 2 -Zimogramas obtidos para as isoenzimas [(A) - PO; (B) - EST], observadas em acessos de pimenta (Capsicum chinense). Sequência dos acessos: A) P9 (BGH 6233-85); B) P8 (BGH 4223-39); C) P7 (BGH 4201-32); D) P6 (BGH 1716-16); E) P5 (BGH 7295-101); F) P4 (BGH 5012-72); G) P3 (BGH 4733-54); H) P2 (BGH 4289-44); I) P1 (BGH 1716-17); J) P10 (BGH 6378-98). 
SOUZA, C.S. et al. Variabilidade genética em acessos de...

(A)

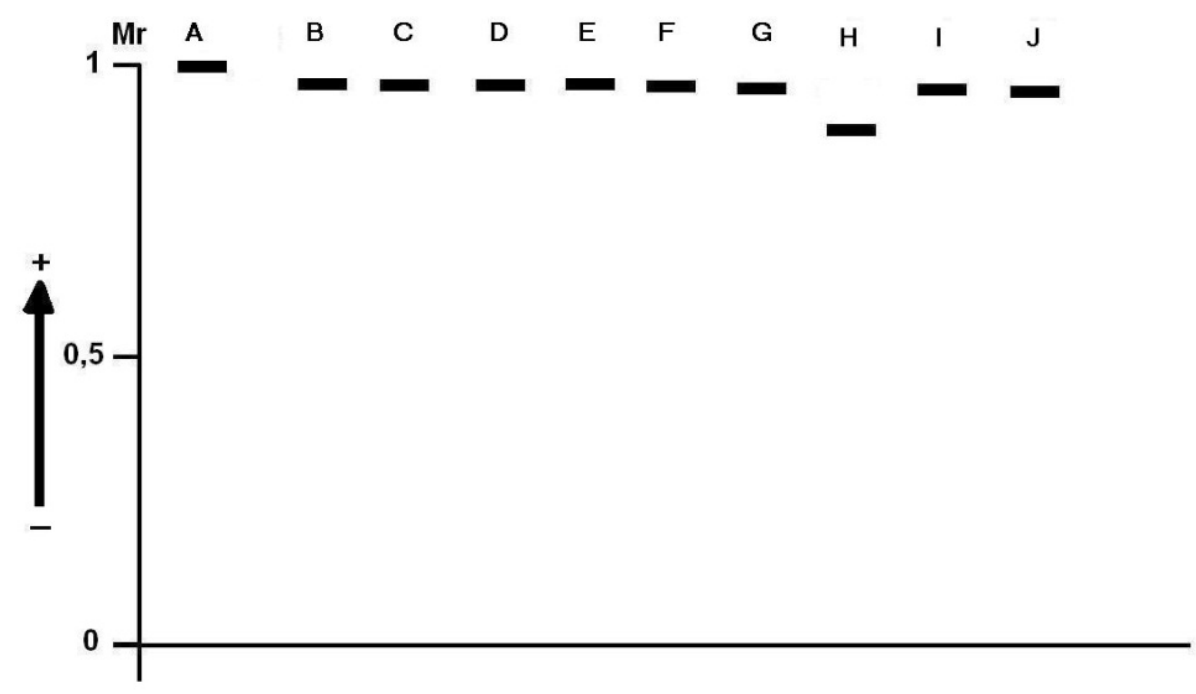

(B)

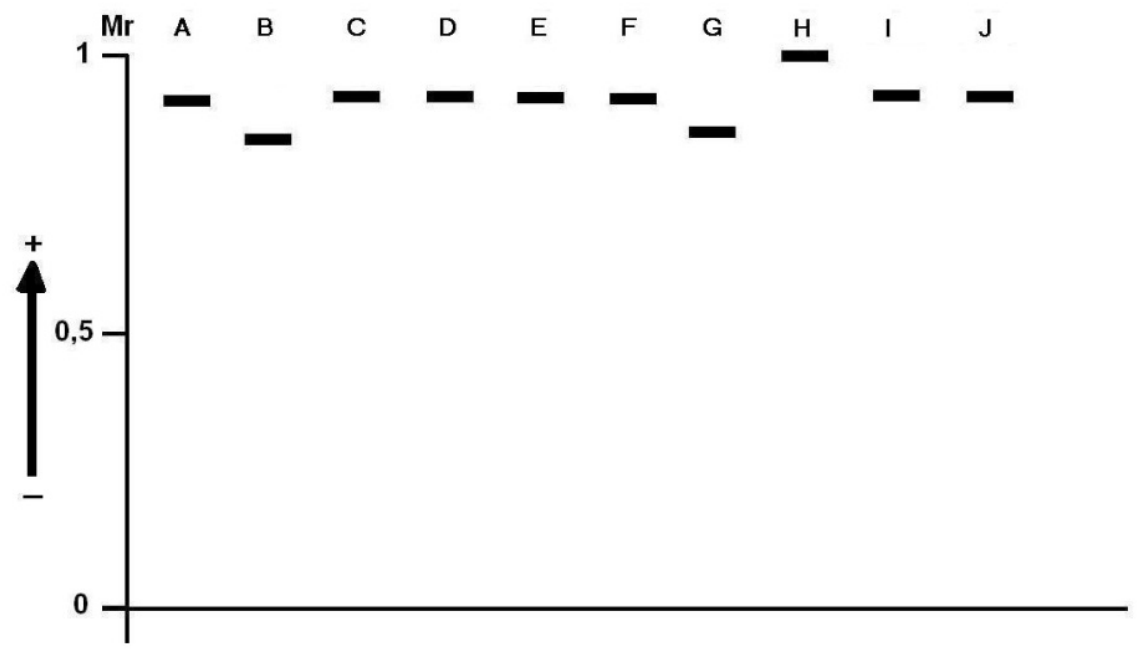

FIGURA 3 -Zimogramas obtidos para as isoenzimas [(A) - GDH; (B) - SKDH], observadas em acessos de pimenta (Capsicum chinense). Sequência dos acessos: A) P9 (BGH 6233-85); B) P8 (BGH 4223-39); C) P7 (BGH 4201-32); D) P6 (BGH 1716-16); E) P5 (BGH 7295-101); F) P4 (BGH 5012-72); G) P3 (BGH 4733-54); H) P2 (BGH 4289-44); I) P1 (BGH 1716-17); J) P10 (BGH 6378-98). 
SOUZA, C.S. et al. Variabilidade genética em acessos de...

(A)

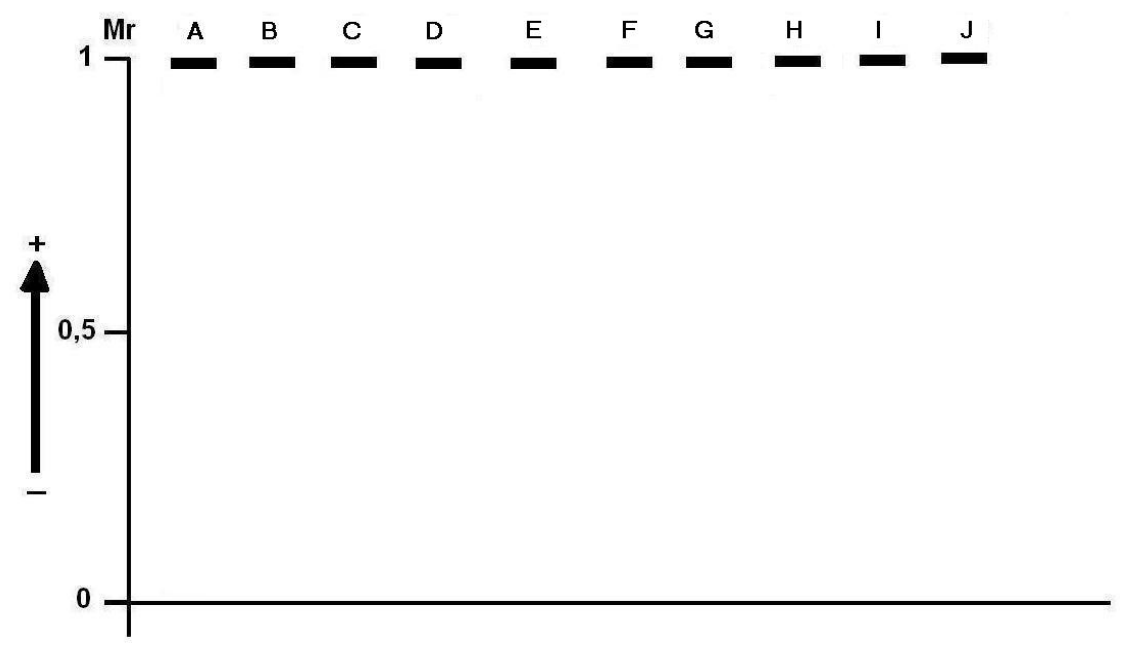

(B)

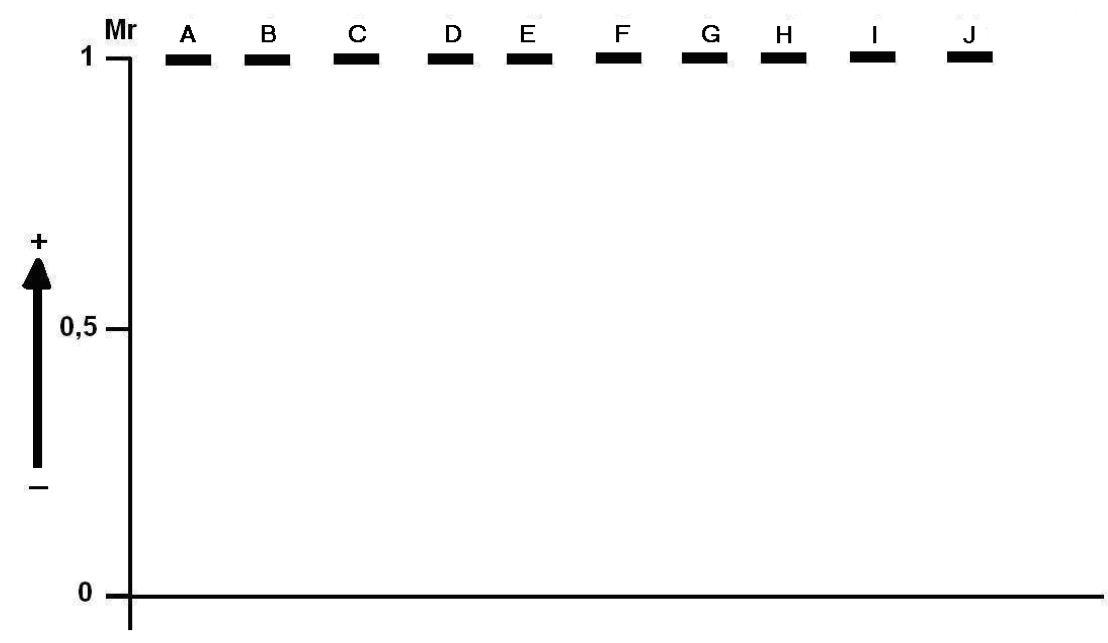

FIGURA 4 -Zimogramas obtidos para as isoenzimas [(A) - G6PDH; (B) - IDH], observadas em acessos de pimenta (Capsicum chinense). Sequência dos acessos: A) P9 (BGH 6233-85); B) P8 (BGH 4223-39); C) P7 (BGH 4201-32); D) P6 (BGH 1716-16); E) P5 (BGH 7295-101); F) P4 (BGH 5012-72); G) P3 (BGH 4733-54); H) P2 (BGH 4289-44); I) P1 (BGH 1716-17); J) P10 (BGH 6378-98). 
SOUZA, C.S. et al. Variabilidade genética em acessos de...

(A)

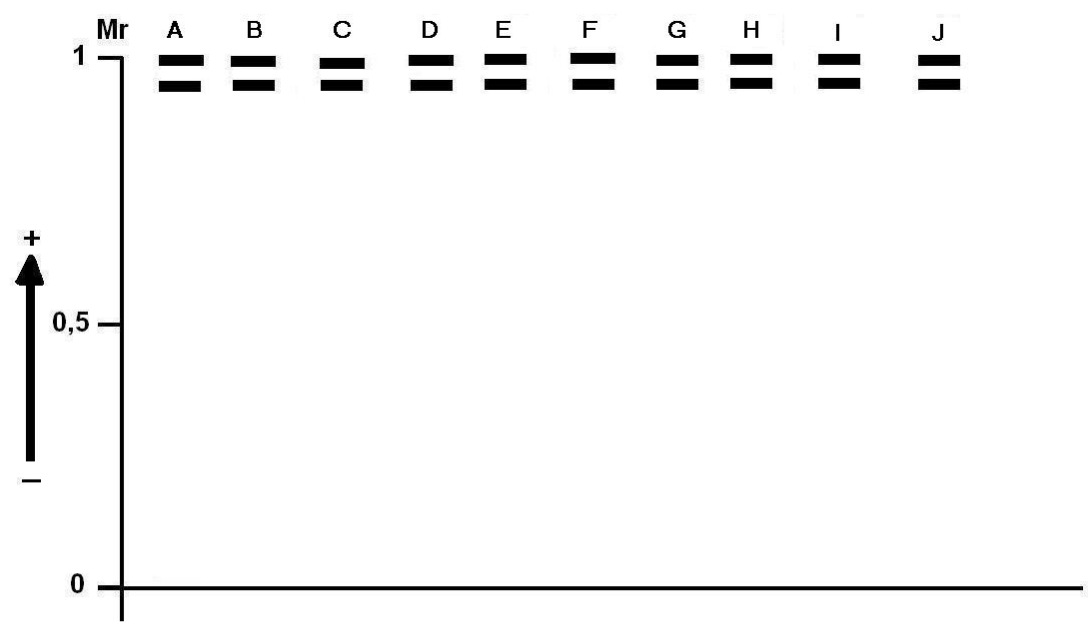

(B)

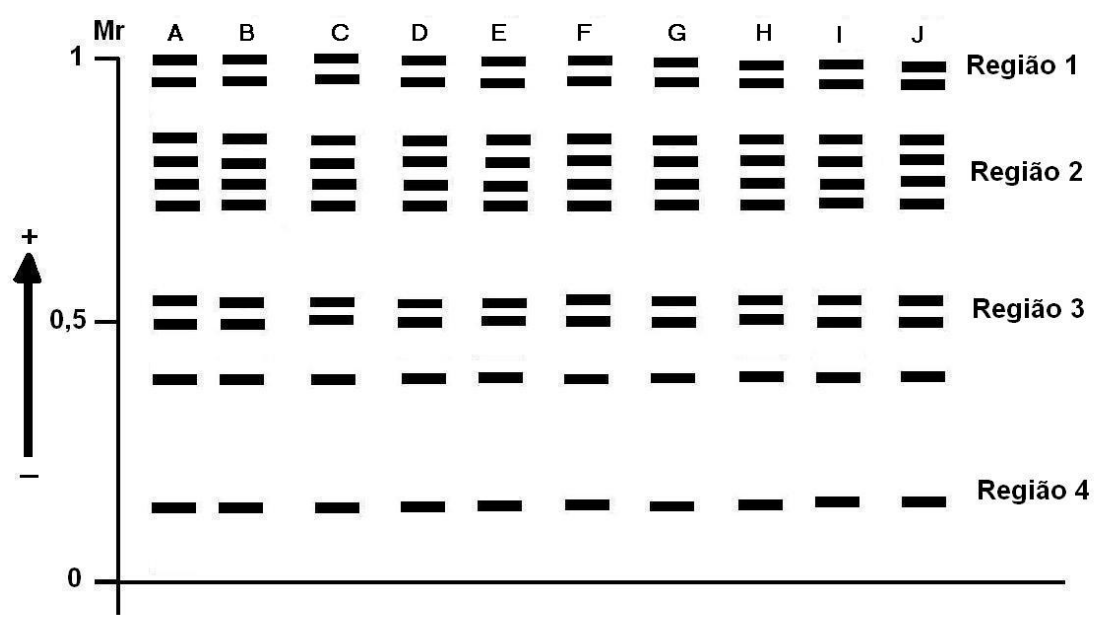

FIGURA 5 -Zimogramas obtidos para as isoenzimas [(A) - GOT; (B) - MDH], observadas em acessos de pimenta (Capsicum chinense). Sequência dos acessos: A) P9 (BGH 6233-85); B) P8 (BGH 4223-39); C) P7 (BGH 4201-32); D) P6 (BGH 1716-16); E) P5 (BGH 7295-101); F) P4 (BGH 5012-72); G) P3 (BGH 4733-54); H) P2 (BGH 4289-44); I) P1 (BGH 1716-17); J) P10 (BGH 6378-98). 
SOUZA, C.S. et al. Variabilidade genética em acessos de...

Deve-se destacar, no entanto, que, no presente trabalho, foram observadas apenas duas bandas, sempre na mesma posição, porém a ausência de polimorfismo e/ou a presença de heterozigose dificulta a determinação do número de cadeias polipeptídicas do sistema enzimático.

Outro sistema que se mostrou monomórfico para os acessos testados foi MDH. Na Figura $5 \mathrm{~B}$, pode-se verificar a presença de um padrão contendo 10 bandas. Como não se detectou a presença de bandas polimórficas, separaram-se as bandas em quatro regiões, porém sem poder concluir quanto à segregação. Em estudo realizado por Schuelter et al. (1999) para Capsicum flexuosum, foi detectada a presença de cinco regiões, sendo possível verificar tanto a presença de enzimas monoméricas como de diméricas. Mcmillin \& Scandalious (1981) detectaram em milho a presença de três locos gênicos que segregam independentemente, e que são denominados Mdh1, Mdh2 e Mdh3. Estes mesmos autores revelaram que o produto do gene Mdh3 interage com Mdh1 ou Mdh2 para formar heterodímeros. De maneira geral, três ou quatro isoenzimas têm sido identificadas em diferentes espécies de plantas e que apresentam atividade no citosol, mitrocôndria e peroxissomos (Gottlieb, 1982 apud Newton, 1983).

Pela análise de agrupamento pelo método de Otimização de Tocher (Tabelas 5 e 6), constatou -se que a distância máxima entre o conjunto de menores distâncias entre cada acesso foi de 0,68, formando, consequentemente, os grupos I e II. Como foi detectada a concentração de nove acessos no grupo I, efetuou-se o subagrupamento, resultando o seguinte: IA - P1 (BGH1716-17), P6 (BGH1716 -16), P7 (BGH4201-32), P10 (BGH6378-98), P9 (BGH6233-85) e P5 (BGH7295-101); IB - P3 (BGH4733-54) e P8 (BGH4223-39); IC - P4 (BGH 5012-72). O acesso P2 (BGH 4289-44) ficouno grupo II.

A distância média entre os grupos I e II foi de 0,72 (Tabela 5), evidenciando que o único integrante do grupo II (P2 - BGH4289-44) é bastante divergente em relação aos demais acessos. Por outro lado, os graus de divergência intragrupo foram similares entre os subgrupos IA e IB, isto é, ambos apresentaram uma distância de 0,26. Como os acessos que compõem o grupo I apresentam maior similaridade genética com base nos marcadores RAPD e isoenzimas, pode-se sugerir que as recombinações neste grupo podem proporcionar variabilidades inferiores, se comparadas entre os grupos I e II. Contudo, os subgrupos IA e IB apresentaram considerável divergência genética em relação ao acesso P4 (BGH5012-72), podendo ser também empregados em futuros cruzamentos.

Com o intuito de confirmar o agrupamento obtido pela técnica de Tocher, realizou-se análise pelo método hierárquico do UPGMA. Pela análise do dendrograma (Figura 6), constatou-se que apesar das metodologias empregarem distintas estratégias de agrupamento, os resultados foram concor- dantes. Contudo, a metodologia do UPGMA permite mostrar, adicionalmente, a relação entre genótipos pertencentes a um mesmo grupo e/ou subgrupo. Pode-se constatar no dendrograma que os acessos que foram agrupados pelo método de Tocher no subgrupo IA apresentaram considerável divergência genética e todos, com exceção dos acessos P1 (BGH1716-17) e P5 (BGH7295-101), são pimentas doces. Neste mesmo subgrupo pode-se constatar que 0 acesso pungente P1 (BGH1716-17) e a pimenta doce P6 (BGH1716-16) apresentaram a menor distância genética, que pode ser explicada pelo fato de fazerem parte da expedição de coleta no município de Pindaré-Mirim/MA e que foram mantidas em separado por conterem características de frutos bastante distintas, além da pungência.

Segundo Schuelter (1996), a diversidade ecogeográfica pode apresentar relevante utilidade quando não se dispõe de informações genéticas sobre a capacidade de combinação dos genótipos e divergência genética entre os mesmos. No presente trabalho, verificou-se que a localização geográfica dos acessos e os resultados das análises obtidas pelos métodos de Tocher e de UPGMA não apresentaram relação, descartando a possibilidade de emprego desse critério na interpretação do agrupamento. Os acessos P3 (BGH4733-54) e P8 (BGH4223-39), por exemplo, que foram agrupados em IB, pertencem a diferentes regiões geográficas, Manaus/AM e Campinas/SP respectivamente. Estes resultados apresentam concordância com alguns trabalhos de pesquisa realizados com espécies de plantas cultivadas e silvestres (Yamada et al., 2002; Vieiraet al., 2007; Siqueira, 2008).

\section{CONCLUSÕES}

Os marcadores RAPD e isoenzimáticos se apresentam viáveis na caracterização de acessos de Capsicum chinense, tendo sido detectados polimorfismos em pimentas pungentes e doces que possibilitam a formação de dois grupos, sendo o grupo I subdividido em três subgrupos. A maior divergência genética é observada entre os acessos P2 (BGH4289-44) e P8 (BGH4223-39), enquanto que os mais similares são os acessos $P 1$ (BGH1716-17) e P6 (BGH1716-16). A análise da divergência genética evidencia que o cruzamento do acesso P2(BGH4289-44) com os demais acessos estudados deve propiciar resultados promissores na obtenção de segregantes superiores no meIhoramento para caracteres de frutos. Finalmente, o atributo pungência de frutos e sua localização geográfica não refletem a magnitude da diversidade genética entre acessos pela análise dos marcadores utilizados.

\section{AGRADECIMENTOS}

A Universidade Paranaense e a Universidade Federal de Viçosa pela disponibilização de recursos financeiros e equipamentos para a realização das análises moleculares. 
SOUZA, C.S. et al. Variabilidade genética em acessos de...

TABELA 5 - Distâncias médias intra e intergrupos entre acessos de pimenta (Capsicum chinense) com base no agrupamento do método de Otimização de Tocher provenientes da avaliação de marcadores isoenzimáticos e RAPD.

\begin{tabular}{|llllll|}
\hline Grupo/Subgrupo & I & IA & IB & IC & II \\
\hline I & 0,47 & - & - & - & 0,72 \\
\hline IA & & 0,26 & 0,43 & 0,44 & - \\
\hline IB & & 0,26 & 0,34 & - \\
\hline IC & & & 0 & - \\
\hline II & & & & & 0 \\
\hline
\end{tabular}

TABELA 6 - Agrupamento dos acessos de pimenta (Capsicum chinense) pelo método de Otimização de Tocher com base no complemento do índice de Jaccard.

\begin{tabular}{|ll|}
\hline Grupo & Acessos \\
\hline IA & P1 (BGH1716-17); P6 (BGH1716-16); P7 (BGH4201-32); \\
& P10 (BGH6378-98); P9 (BGH6233-85); P5 (BGH7295-101) \\
\hline IB & P3 (BGH4733-54); P8 (BGH4223-39) \\
\hline IC & P4 (BGH5012-72) \\
\hline II & P2 (BGH 4289-44) \\
\hline
\end{tabular}

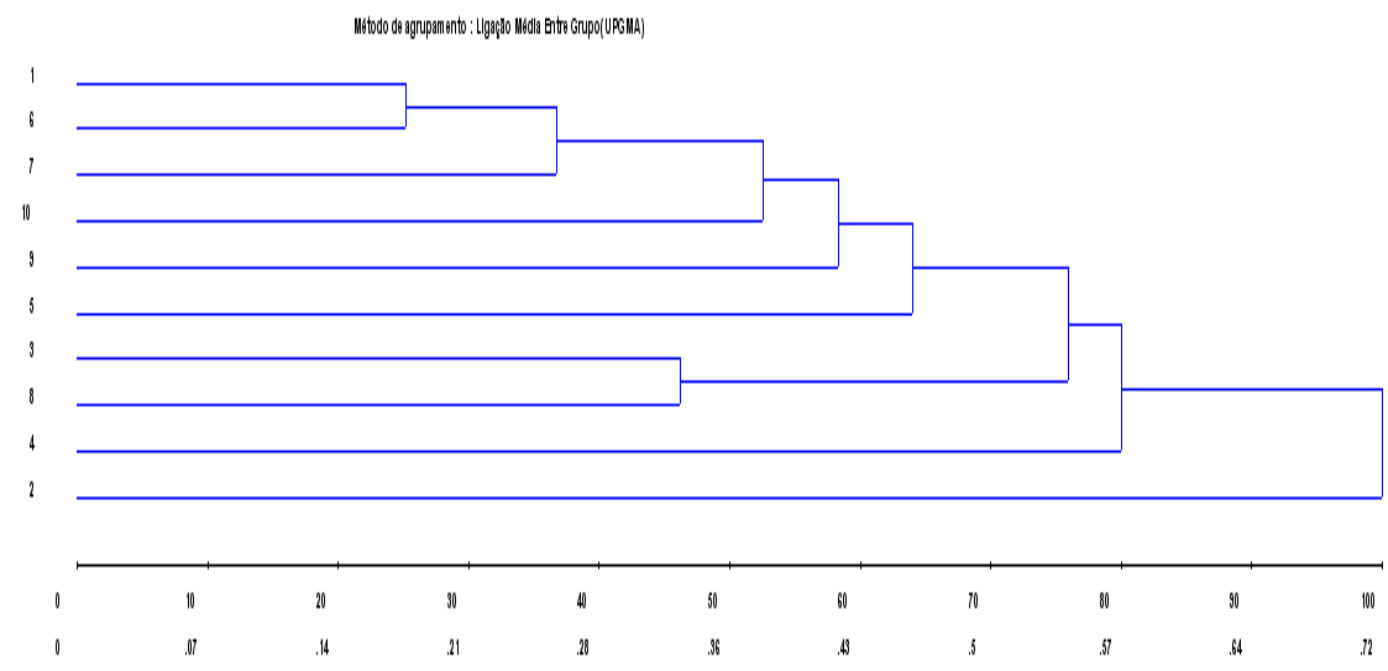

FIGURA 6 - Dendrograma estabelecido pelo método do UPGMA dos acessos P1 (BGH 1716-17); P2 (BGH 4289-44); P3 (BGH 4733-54); P4 (BGH 5012-72); P5 (BGH 7295-101); P6 (BGH 1716-16); P7 (BGH 420132); P8 (BGH 4223-39); P9 (BGH 6233-85); P10 (BGH 6378-98) de pimenta (Capsicum chinense), com base no complemento do Índice de Jaccard. 
SOUZA, C.S. et al. Variabilidade genética em acessos de...

\section{REFÊRÊNCIAS}

1.ALFENAS, A.C.; PETERS, I.; BRUNE, W.; PASSADOR, G.C. Eletroforese de proteínas e isoenzimas de fungos e essências florestais. Viçosa: Imprensa Universitária, 1991.

2.BEN-CHAIM, A.; BOROVSKY, Y.; FALISE, M.; MAZOUREK, M.; KANG, B.; PARAN, I.; JAHN, M. QTL analysis for capsaicinoid content in Capsicum.Theoretical Applied Genetics,v.113, n.8, p.1481-1490, 2006.

3.BRICKELL, C. Enciclopedia de plantas e flores de la real Sociedad de horticultura.Barcelona: Ediciones Grijalbo, 1989.

4.BRUNE, W.; ALFENAS, A.C.; JUNGHANS, T.G. Identificações específicas de enzimas em géis. In: ALFENAS, A.C. (Ed.). Eletroforese de isoenzimas e proteínas afins: fundamentos e aplicações em plantas e microorganismos. Viçosa UFV, 1998. p.201-328.

5.CASALI, V.W.D.; COUTO, F.A. Origem botânica de Capsicum. Informe Agropecuário, v.113, p. 08-10, 1984.

6.COSTA, F.R.; PEREIRA, T.N.S.; SUDRÉ, C.P.; RODRIGUES, R. Marcadores RAPD e caracteres morfoagronômicos na determinação da diversidade genética entre acessos de pimentas e pimentões. Ciência Rural, v.39, n.3, p. 696-704, 2008.

7.CRUZ, C.D. Programa Genes: biometria. Editora UFV, Viçosa. 2006b.

8.CRUZ, C.D. Programa Genes: estatística experimental e matrizes. Editora UFV, Viçosa. 2006a.

9.DJIAN-CAPORALINO, C.; PIJAROWSKI, L.; FAZARI, A.; SAMSON, M.; GAVEAU, L.; O’BYRNE, C.; LEFEBVRE, V.; CARANTA, C.; PALLOIX, A.; ABAD, P.High-resolution genetic mapping of the pepper (Capsicum annuum L.) resistance loci $\mathrm{Me} 3$ and Me4 conferring heat-stable resistance to root-knot nematodes (Meloidogyne spp.).Theoretical and Applied Genetics, v.103, n.4, p.592-600, 2001.

10.DOYLE, J.J.; DOYLE, J.L. Isolation of plant DNA from fresh tissue. Focus, v.1, p. 13-15, 1991.

11.GAIA, J.M.D.; MOTA, M.G.C.; DERBYSHIRE, M.T.V.C.; OLIVEIRA, V.R.; COSTA, M.R.; MARTINS, C. da S.; POLTRONIERI, M.C. Caracterização de acessos de pimenta-do-reino com base em sistemas enzimáticos. Horticultura Brasileira, v.25, n.3, p. 333-342, 2007.

12.GREENLEAF, W. H. Pepper breeding. In: BASSET, M. J. (Ed.). Breeding vegetable crops. Connecticut: AVI, 1986. p.69134.

13.GUZMÁN, F.A.; AYALA, H.; AZURDIA, C.; DUQUE, M.C.; VICENTE, M.C. de.AFLP Assessment of genetic diversity of Capsicum genetic resources in Guatemala: home gardens as an option for conservation. Crop Science,v.45, n.1, p.363-370, 2005.

14.HEISER Jr, C.B. Peppers. Capsicum (Solanaceae). Evolution of crop plants. London: Longman, 1976. p.265-268.

15.HUH, J.H.; KANG, B.C.; NAHM, S.H.; KIM, S.; HA, K.S.; LEE, M.H.; KIM, B.D. A candidate gene approach identified phytoene synthase as the locus for mature fruit color in red pepper (Capsicum spp.). Theoretical and Applied Genetics, v.102, n.4, p.524-530, 2001.

16.KOCHIEVA, E.Z.; RYZHOVA, N.N. Molecular AFLP analysis of the genotypes of pepper Capsicum annuum cultivars.Russian.Journal of Genetics,v.39, n.12, p.1345-1348, 2003.

17.LANNES, S.D. Diversidade em Capsicum chinense: análise química, morfológica e molecular. 2005. Tese. (Doutorado em Genética e Melhoramento) - Universidade Federal de Viçosa, Viçosa.

18.LEE, H.R.; BAE, I.H.; PARK, S.W.; KIM, H.J.; MIN, W.K.; HAN, J.H.; KIM, K.T.; KIM, B.D. Construction of an integrated pepper map using RFLP, SSR, CAPS, AFLP, WRKY, rRAMP and BAC end sequences. Molecular Cells, v.27, n.1, p.21-37, 2009.

19.LEFEBVRE, V.; GOFFINET, B.; CHAUVET, J.C.; CAROMEL, B.; SIGNORET, P.; BRAND, R.; PALLOIX, A. Evaluation of genetic distances between pepper inbred lines for cultivar protection purposes: comparison of AFLP, RFLP and phenotypic data. Theoretical and Applied Genetics, v.102, n.4, p. 741-750, 2001.

20.LEFEBVRE, V.; PALLOIX, A.; CARANTA, C.; POCHARD, E. Construction of an interespecific integrated linkage map of pepper using molecular marker and double haploid progenies. Genome, v. 38, n.1, p. 112-121, 1995.

21.LOPES, R.; BRUCKNER, C.H.; LOPES, M.T.G. Polimorfismo isozimático e potencial de utilização das isozimas como marcadores genéticos em aceroleira. Pesquisa Agropecuária Brasileira, v.37, n.2, p. 151-158, 2002.

22.LOPES, R.C.; CASALI, V.W.D.; BARBOSA, L.C.A.; CECON, P.R. Caracterização isoenzimática de oito acessos de Ervade-bicho. Horticultura Brasileira, v. 21, n. 3, p. 433-437, 2003.

23.McMILLIN, D.E.; SCANDALIOS, J.G. Genetics analysis of the two groups of duplicated genes coding for mitochondrial malate dehydrogenase in Zea mays. Molecular and General Genetics, v.182, n.2, p.211-221, 1981.

24.MINAMIYAMA, Y.; TSURO, M.; KUBO, T.; HIRAI, M. QTL analysis for resistance to Phytophthora capsici in pepper using a high density SSR-based map. Breeding Science, v.57, n.2, p.129-134, 2007.

25.MONSEREENUSORN, Y.; KONGSAMUT, S.E; PEZALLA. P.D. Capsicum: a literature survey. Critical Reviews in Toxicology, v. 10, n.4, p. $321,1982$.

26.NEWTON, K.J. Genetics of mitochondrial isozymes. In: Tanksley, S.D.; Orton, T.J. Isozymes in plant genetics and breeding - Parte A. New York: Editora Elsevier, 1983.

27.PARAN, I.; AFTERGOOT, E.; SHIFRISS, C. Variation in Capsicum annum revealed by RAPD and RFLP markers. Euphytica, v. 99, n.3, p. 167-173, 1998

28.PEREIRA, G.M. Análise dialélica e pungência dos frutos em Capsicum chinense. 2007. Tese. (Doutorado em Genética e Melhoramento) - Universidade Federal de Viçosa, Viçosa.

29.PICKERSGILL, B. Numerical taxonomic studies on variation and domestication in some species of Capsicum. In: HAWKES, J. G. The Biology and Taxonomy of the Solanaceae. London: Academic Press, 1980. p. 49-86.

30.PRINCE, J.P.; LACKNEY, V.K.; ANGELES, C.; BLAUTH, J.R.; KYCE, M.M. A survey of DNA polymorphism within the genes Caps on the fingerprint of pepper cultivar. Genome,v. 38, p. 224-231, 1995.

31.REIFSCHNEIDER, F. J. B. (Org.). Capsicum: pimentas e pimentões no Brasil. Brasília: Embrapa Comunicação para Transferência de Tecnologia: Embrapa Hortaliças, 2000.

32.RODRIGUEZ, J.M.; BERKE, T.; ENGLE, L.;NIENHUIS, J.Variation among and within Capsicum species revealed by RAPD markers. Theoretical and Applied Genetics, v.99, n.1/2, p. 147-156, 1999.

33.SAWAZAKI, H.E.; NAGAI, H.; SODEK, L. Caracterização da variabilidade genética em couve-manteiga utilizando isoenzimas e RAPD. Horticultura Brasileira, v.56, n.1, p. 9-19, 1997.

34.SCHUELTER, A. R.; CASALI, V.W.D.; FINGER, F.L. Inheritance of malate dehydrogenase in wild pepper Capsicum flexuosum Sendt. Bragantia, v.58, n.1, p. 1-6, 1999. 
SOUZA, C.S. et al. Variabilidade genética em acessos de...

35.SCHUELTER, A.R. Análise isozimática, dialélica e diversidade genética da pimenta silvestre (Capsicum flexuosum Sendt.). 1996. Dissertação. (Mestrado em Genética e Melhoramento) - Universidade Federal de Viçosa, Viçosa.

36.SCHUELTER, A.R.; PEREIRA, G.M.; AMARAL JUNIOR, A.T.; CASALI, V.W.D.; SCAPIM, C.A.; SILVA, W.; FINGER, F.L.Genetic control of agronomically important traits of pepper fruits analyzed by Hayman's partial diallel cross scheme. Genetics and Molecular Research, v.9, n.1, p. 113-127, 2010.

37.SIQUEIRA, M.V.B.M. Diversidade genética de etnovariedade de mandioca (Manihot esculenta Crantz) em áreas de Cerrado no Estado do Mato Grosso do Sul e de variedades comerciais por meio de marcadores microssatélites. 2008. Dissertação. (Mestrado em Ecologia de Agroecossistemas) - ESALQ/Universidade do Estado de São Paulo, Piracicaba.

38.SOUZA, R. J.; CASALI, W.D. Cultivares de pimentão e pimenta. Informe Agropecuário, v. 1, n.113, p. 15-18. 1984.

39.VIEIRA, V.C.; ALVES, P.L.C.A.; LEMOS, M.V.F.; SENA, J.A.D. Variabilidade genética de acessos de trapoeiraba (Commelina benghalensis L.).Arquivos do Instituto Biológico, v.74, n.4, p.515-320, 2007.

40.WILLIAMS, J.G.K.; KUBELIK, A.R.; LIVAK, K.J.; RAFALSKI, J.A.; TINGEY, S.V. DNA polymorphism amplifiedby arbitrary primers are useful as genetic markers. Nucleic Acids Research, v. 18, n.22, p. 6531-6535, 1990.

41.YAMADA, M.M.; FALEIRO, F.G.; LOPES, U.V.; DANTAS NETO, A.; PIRES, J.L.; FLORES, A.B.; FALEIRO, A.S.G.; BAHIA, R.C.S. Diversidade genética de acessos de cacaueiro da Série CEPEC por meio de marcadores RAPD. Agrotrópica v.14, n.3, p.137-140, 2002.

42.YI, G.; LEE, J.M.; LEE, S.; CHOI, D.; KIM, B.D. Exploitation of pepper EST-SSRs and an SSR-based linkage map. Theoretical and Applied Genetics, v.114, n.1, p. 113-130, 2006.

Recebido em 22/02/2011

Aceito em 22/03/2013 